\title{
Fungos micorrízicos arbusculares (FMA) em porta-enxertos micropropagados de videira
}

\author{
Rafael Anzanello $\left({ }^{(*)}\right)$; Paulo Vitor Dutra de Souza $\left({ }^{2}\right)$; Bruno Casamali $\left({ }^{2}\right)$ \\ (') Universidade Federal do Rio Grande do Sul (UFRGS), Faculdade de Agronomia, Programa de Pós-Graduação, \\ Av. Bento Gonçalves, 7712, 91501-970 Porto Alegre (RS). \\ (2) UFRGS, Departamento de Horticultura e Silvicultura, 91501-970 Porto Alegre (RS). \\ (*) Autor correspondente: ranzanello@yahoo.com.br
}

Recebido: 18/fev./2009; Aceito: 13/out./2010.

\begin{abstract}
Resumo
O uso de fungos micorrízicos na produção de mudas de videira é importante alternativa para acelerar o desenvolvimento inicial das plantas. Este trabalho teve por objetivo avaliar o comportamento de dois FMA sobre o crescimento vegetativo de três porta-enxertos (PE) de videira. Foram utilizados os FMA Glomus etunicatum e Scutellospora heterogama e os PE SO4, Paulsen 1103 e 043-43. Os PE, oriundos de micropropagação, foram transferidos e aclimatizados em copos plásticos de $300 \mathrm{~mL}$ e após 58 dias transplantados para sacos plásticos de $2 \mathrm{~L}$ de capacidade, contendo como substrato uma mistura de casca de arroz carbonizada e Plantmax ${ }^{\circledR}$ na proporção de 1:1 v/v. Utilizaram-se, como inóculo, 20 g de solo rizosférico mais fragmentos de raízes contendo as estruturas dos FMA, adicionados ao substrato na fase de aclimatização. Aos 135 dias após inoculação, foram avaliadas as massas de matéria fresca e seca das raízes e parte aérea, comprimento de raízes e parte aérea, diâmetro de colo e teores de nutrientes da parte aérea. Os FMA Glomus etunicatum e Scutellospora heterogama proporcionaram melhor nutrição e maior crescimento vegetativo dos porta-enxertos de videira, se comparadas as plantas testemunhas. Os benefícios oriundos da simbiose dependeram da combinação específica entre o isolado fúngico e a variedade de porta-enxerto utilizada, sendo o 043-43 beneficiado preponderantemente pelo FMA Glomus etunicatun e o SO4 e Paulsen 1103 por Glomus etunicatum e Scutellospora heterogama.
\end{abstract}

Palavras-chave: endomicorrizas, propagação, mudas, Vitis sp.

\section{Use of arbuscular mycorrhizal (AMF) fungi in micropropagated grape rootstocks}

\section{Abstract}

The use of mycorrhizal fungi is an activity of great importance to accelerate the initial development of grape seedlings. This work aimed to evaluate the effects of two AMF on the vegetative growth of three grape rootstocks. Such experiment used the arbuscular mycorrhizal fungi Glomus etunicatum and Scutellospora heterogama, and the rootstocks S04, Paulsen 1103 e 043-43. The micropropagated rootstocks were transferred and acclimated in $300 \mathrm{~mL}$ plastic cups, and after 58 days were transplanted to $2 \mathrm{~L}$ plastic bags containing a mixture of carbonized rice husks and Plantmax ${ }^{\circledR}$ on the proportion 1:1, as substrate. The inoculum consisted of $20 \mathrm{~g}$ of rhizospheric soil and roots fragments containing the structures of AMF added to the substrate during the acclimatization stage. Fresh and dry matter of roots and shoots, length of roots and shoots, stem diameter and nutritional status of shoots were evaluated after 135 days of inoculation. The AMF Glomus etunicatum and Scutellospora heterogama provided better nutrition and greater vegetative growth of rootstock varieties when compared to the non-inoculated plants. The benefits of symbiosis were depended on the specific combination of the fungal isolate and rootstock variety employed, with 043-43 benefited mainly by AMF Glomus etunicatun and SO4 and Paulsen 1103 by Glomus etunicatum and Scutellospora heterogama.

Key words: endomycorrhizae, propagation, stock plants, Vitis sp. 


\section{INTRODUÇÃO}

A produção de plantas em escala comercial pode ser beneficiada pela obtençáo de mudas de alta qualidade e homogeneidade em curtos períodos de tempo através da micropropagação (Locatelli e Lovato, 2002). Entre as diversas vantagens que a micropropagação proporciona na produção rápida de mudas, em larga escala está a eliminaçáo de microrganismos potencialmente fitopatogênicos (Agostini, 2002). No entanto, também sáo eliminados microrganismos que podem favorecer o estabelecimento das mudas micropropagadas e seu crescimento, como os FMA (ZemKLE et al., 2003).

As associações mutualísticas, entre os fungos micorrízicos e as raízes da maioria das plantas conferem papel fundamental na sobrevivência, no crescimento e desenvolvimento das plantas (Silveira et al., 2002; Nunes et al., 2008a). As micorrizas são amplamente reconhecidas pelo efeito positivo que proporcionam no crescimento da planta, no aumento da absorção de nutrientes, especialmente o P, pelo maior do volume de solo explorado e conferem maior tolerância aos estresses bióticos e abióticos (Schreiner, 2007; Nunes et al., 2008b).

A introdução de FMA nos programas de produção de mudas micropropagadas representa grande potencial agronômico (Thomas e Ravindra, 1997; Saggin Júnior e LovaTO, 1999). Além de aumentar o vigor e a capacidade de sobrevivência das plantas, pelo aumento na absorção de nutrientes, as micorrizas podem aumentar a tolerância aos patógenos radiculares e reduzir o nível de aplicação de fertilizantes após o transplante (Nogales et al., 2009). Além disso, assegura uma rápida formação, redução no tempo de aclimatização e maior homogeneidade das plantas durante $\mathrm{o}$ crescimento inicial no campo (Locatelli e Lovato, 2002).

Para se obter os benefícios que a inoculação com FMA promove nas plantas micropropagadas é de fundamental importância que a associação micorrízica seja estabelecida em curto período de tempo (Zemkle et al., 2003). Além disso, Thomas e Ravindra (1997) e Locatelli e Lovato (2002) relatam que os benefícios oriundos da simbiose dependem da combinação específica entre $\mathrm{o}$ isolado fúngico $\mathrm{e}$ a variedade de porta-enxerto da cultura frutífera utilizada.

Considerando os efeitos benéficos da associação planta: FMA e sua especificidade com porta-enxertos, este trabalho tem por objetivo avaliar a utilização de diferentes FMA sobre o crescimento vegetativo de três porta-enxertos micropropagados de videira.

\section{MATERIAL E MÉTODOS}

Foram utilizados três porta-enxertos (PE) de videira: $\mathrm{SO} 4$ (Vitis berlandieri x Vitis riparia), Paulsen 1103 (Vitis berlandieri $\mathrm{x}$ Vitis rupestris) e 043-43 (Vitis vinifera $\mathrm{x}$ Vitis rotundifolia) e duas espécies de FMA: FMA1 - Glomus etunicatum e FMA2 - Scutellospora heterogama. Os inóculos de FMA consistiram de solo rizosférico (substrato: solo + areia esterilizados, 1:1, v:v) e raízes de aveia (Avena sp.) contendo estruturas dos fungos conforme recomendado por Menge (1984).

Os PE SO4, Paulsen 1103 e 043-43 são comercialmente empregados na viticultura no Brasil (GiovaninnI, 2008). O PE SO4 é muito difundido no Rio Grande do Sul. Imprime alto vigor à copa, adaptando-se bem a solos de textura franca a argilosa, com média sensibilidade a fusariose. O PE Paulsen 1103 possui alta tolerância à fusariose e boa afinidade com diversas cultivares, tanto de mesa como para processamento, sendo altamente propagado no Rio Grande do Sul e em Santa Catarina. É vigoroso e adapta-se bem a solos de textura arenosa a argilosa. O PE 043-43 imprime alto vigor à copa, sendo recomendado para cultivares de mesa. Além disso, confere boa resistência à pérola-da-terra e à fusariose, conforme descrito por BotelHo et al. (2005).

Para a produção das mudas micropropagadas, explantes compostos por duas gemas dos $\mathrm{PE}$ foram colocados em meio DSD1 (Silva e Doazan, 1995) com sacarose $\left(20,0 \mathrm{~g} \mathrm{~L}^{-1}\right)$ e ágar $\left(5,5 \mathrm{~g} \mathrm{~L}^{-1}\right)$, isento de reguladores de crescimento e o $\mathrm{pH}$ ajustado para 6,4, sendo uma das gemas imersa no meio com ágar para a formação das raízes e uma gema aérea para a emissão da brotação. Os frascos foram mantidos em câmaras de crescimento durante 40 dias a $25 \pm 1{ }^{\circ} \mathrm{C}$, fotoperíodo de 16 horas e radiação fotossinteticamente ativa de $40 \mathrm{a} 45 \mathrm{mmol} \mathrm{m} \mathrm{m}^{-2}$ ao nível do frasco, até as plantas atingirem altura em torno de $15 \mathrm{~cm}$. Posteriormente, os porta-enxertos foram transplantados e aclimatizados em casa de vegetação por 58 dias em copos de polietileno de $300 \mathrm{~mL}$, contendo substrato esterilizado em autoclave a $120{ }^{\circ} \mathrm{C}$ por 15 minutos, constituído de uma mistura de casca de arroz carbonizada e Plantmax ${ }^{\oplus}$ na proporção de $1: 1 \mathrm{v} / \mathrm{v}$. Cada recipiente recebeu uma camada de $20 \mathrm{~g}$ de inóculo de FMA, disposta na parte mediana do recipiente em contato com o sistema radicular dos PE. As plantas testemunhas foram transplantadas sem a inoculação com FMA. Em seguida, as plantas foram transferidas para sacos de polietileno pretos de dois litros contendo o mesmo substrato da mistura descrita anteriormente, sendo cultivadas e avaliadas aos 77 dias.

A irrigação foi realizada em intervalos de 48 horas, adicionando-se $20 \mathrm{~mL}$ de água por planta, quando cultivadas em copos de polietileno e, $100 \mathrm{~mL}$ de água por planta, quando cultivadas em sacos plásticos. A temperatura média, na casa de vegetação, ao longo do experimento foi de $19,5^{\circ} \mathrm{C}$, com a média das mínimas de $15,6^{\circ} \mathrm{C}$ e das máximas de $23,5^{\circ} \mathrm{C}$. O substrato não foi adubado durante todo o período experimental.

O delineamento utilizado foi o completamente casualizado com 16 repetiçóes, sendo uma planta por parcela. Os tratamentos testados foram os seguintes: S04 - não inoculado (Testemunha); Paulsen 1103 - não inoculado 
(Testemunha); 043-43 - não inoculado (Testemunha); SO4 - submetido à inoculação com Glomus etunicatum; Paulsen 1103 - com Glomus etunicatum; 043-043 - com Glomus etunicatum; SO4 - com Scutellospora heterogama; Paulsen 1103 - com Scutellospora heterogam e 043-43 com Scutellospora heterogama.

Para todos os tratamentos foram avaliadas as variáveis associadas à matéria fresca das raízes (MFR), matéria fresca da parte aérea (MFPA), matéria seca das raízes (MSR), matéria seca da parte aérea (MSPA), comprimento da parte área (CPA), comprimento das raízes (CR), diâmetro do colo e análise nutricional da parte aérea.

A matéria fresca foi obtida mediante a separação das raízes e da parte aérea com imediata pesagem dos tecidos $\left(\mathrm{g} \mathrm{pl}^{-1}\right)$. Posteriormente, o material foi submetido à secagem em estufa, com circulação forçada de ar, a $65^{\circ} \mathrm{C}$, até massa constante, e novamente pesado para a obtenção da matéria seca. Os comprimentos das raízes e da parte aérea foram obtidos usando-se uma régua $\left(\mathrm{cm} \mathrm{pl}^{-1}\right)$ e o diâmetro do colo através de leitura com paquímetro $(\mathrm{mm})$.

Para a análise nutricional, após a secagem, o material foi moído e dividido em três repetições. A determinação dos macronutrientes $\mathrm{N}, \mathrm{P}, \mathrm{K}, \mathrm{Ca}$ e $\mathrm{Mg}$ foi realizada de acordo com TeDesco et al. (2004), sendo os resultados expressos em \%.

Os resultados foram analisados pelo teste $\mathrm{F}$ e as médias comparadas pelo teste de Duncan, $\mathrm{p} \leq 0,05$.

\section{RESULTADOS E DISCUSSÃO}

A partir da inoculação com os FMA até a transferência das plantas para os sacos plásticos de dois litros (58 dias), não houve diferença significativa entre os tratamentos em relação ao comprimento da parte área das plantas (dados não mostrados). A ausência de efeito dos FMA neste período pode ser explicada de duas maneiras. Primeiramente, o tempo pode ter sido insuficiente para o endófito ter mostrado sua eficiência, pois necessitou inicialmente colonizar as raízes, período em que o fluxo de metabólitos é maior no sentido da muda para o FMA do que o inverso. Aliado a isto, as raízes dos PE podem ter sido capazes de explorar todo o volume de substrato contido no recipiente de $300 \mathrm{~mL}$, dispensando o auxílio dos FMA. Agostini (2002), após 91 dias da inoculação de PE de videira com FMA, também verificou que as espécies estudadas estavam ainda ineficientes em promover maior crescimento das plantas.

Em contrapartida, aos 135 dias de inoculação (77 dias de cultivo em recipientes de $2 \mathrm{~L}$ ), combinaçóes específicas entre FMA e PE promoveram diferenças significativas no crescimento e desenvolvimento dos $\mathrm{PE}$, quando comparadas às plantas testemunhas (Tabelas 1, 2, 3 e 4), confirmando que o tempo de inoculaçáo e/ou o volume do recipiente são fatores determinantes para a colonização e para a ação micorrízica sobre as plantas (Agostini, 2002).

Tabela 1. Matéria fresca da parte aérea e matéria seca da parte aérea de porta-enxertos de videira Vitis sp. não submetidos à inoculação (Testemunha) e com inoculação de fungos micorrízicos arbusculares Glomus etunicatum e Scutellospora heterogama

\begin{tabular}{|c|c|c|c|c|c|c|}
\hline \multirow{3}{*}{ Porta-enxerto } & \multicolumn{3}{|c|}{ Matéria fresca da parte aérea } & \multicolumn{3}{|c|}{ Matéria seca da parte aérea } \\
\hline & Testemunha & $\begin{array}{c}\text { Glomus } \\
\text { etunicatum }\end{array}$ & $\begin{array}{c}\text { Scutellospora } \\
\text { heterogama }\end{array}$ & Testemunha & $\begin{array}{c}\text { Glomus } \\
\text { etunicatum }\end{array}$ & $\begin{array}{c}\text { Scutellospora } \\
\text { heterogama }\end{array}$ \\
\hline & \multicolumn{3}{|c|}{$\mathrm{g} \mathrm{pl}^{-1}$} & \multicolumn{3}{|c|}{$\mathrm{g} \mathrm{pl}^{-1}$} \\
\hline SO4 & 20,02 bB & 29,07 bA & 32,44 aA & $5,68 \mathrm{aB}$ & $8,07 \mathrm{bA}$ & $9,20 \mathrm{aA}$ \\
\hline Paulsen 1103 & 18,95 bB & $20,54 \mathrm{cAB}$ & $23,79 \mathrm{bA}$ & $5,60 \mathrm{aA}$ & $5,93 \mathrm{cA}$ & $6,64 \mathrm{bA}$ \\
\hline 043-43 & $24,45 \mathrm{aB}$ & $52,00 \mathrm{aA}$ & $24,87 \mathrm{bB}$ & $6,53 \mathrm{aB}$ & $12,72 \mathrm{aA}$ & $8,33 \mathrm{bB}$ \\
\hline C.V. (\%) & \multicolumn{3}{|c|}{20,32} & \multicolumn{3}{|c|}{16,87} \\
\hline
\end{tabular}

Médias seguidas por letra maiúscula distinta na linha e minúscula na coluna, dentro da variável matéria fresca da parte aérea, diferem significativamente pelo teste de Duncan, $\mathrm{p} \leq$ 0,05. Médias seguidas por letra maiúscula distinta na linha e minúscula na coluna, dentro da variável massa de matéria seca da parte aérea, diferem significativamente pelo teste de Duncan, $\mathrm{p} \leq 0,05$.

Tabela 2. Matéria fresca de raízes e matéria seca de raízes de porta-enxertos de videira Vitis sp. não submetidos à inoculação (Testemunha) e com inoculação de fungos micorrízicos arbusculares Glomus etunicatum e Scutellospora heterogama

\begin{tabular}{|c|c|c|c|c|c|c|}
\hline \multirow{3}{*}{ Porta-enxerto } & \multicolumn{3}{|c|}{ Matéria fresca de raízes } & \multicolumn{3}{|c|}{ Matéria seca de raízes } \\
\hline & Testemunha & $\begin{array}{l}\text { Glomus } \\
\text { etunicatum }\end{array}$ & $\begin{array}{l}\text { Scutellospora } \\
\text { heterogama }\end{array}$ & Testemunha & $\begin{array}{c}\text { Glomus } \\
\text { etunicatum }\end{array}$ & $\begin{array}{c}\text { Scutellospora } \\
\text { heterogama }\end{array}$ \\
\hline & \multicolumn{3}{|c|}{$\mathrm{g} \mathrm{pl}^{-1}$} & \multicolumn{3}{|c|}{$\mathrm{g} \mathrm{pl}^{-1}$} \\
\hline SO4 & $10,19 \mathrm{abc}$ & 14,66 bB & $17,80 \mathrm{aA}$ & $3,02 \mathrm{aB}$ & $3,99 \mathrm{abAB}$ & 4,10 aA \\
\hline Paulsen 1103 & 9,08 bA & $9,24 \mathrm{cA}$ & $10,31 \mathrm{bA}$ & 2,86 aA & $2,89 \mathrm{bA}$ & 3,39 aA \\
\hline $043-43$ & $13,32 \mathrm{aC}$ & $24,35 \mathrm{aA}$ & $18,86 \mathrm{aB}$ & $3,23 \mathrm{aB}$ & $4,60 \mathrm{aA}$ & $4,17 \mathrm{aAB}$ \\
\hline C.V. (\%) & \multicolumn{3}{|c|}{23,67} & \multicolumn{3}{|c|}{14,62} \\
\hline
\end{tabular}

Médias seguidas por letra maiúscula distinta na linha e minúscula na coluna, dentro da variável matéria fresca de raízes, diferem significativamente pelo teste de Duncan, p $\leq$, 05 . Médias seguidas por letra maiúscula distinta na linha e minúscula na coluna, dentro de massa de matéria seca de raízes, diferem significativamente pelo teste de Duncan, p 0,05 . 
Tabela 3. Comprimento de raízes e comprimento da parte aérea de porta-enxertos de videira Vitis sp. não submetidos à inoculação (Testemunha) e com inoculação de fungos micorrízicos arbusculares Glomus etunicatum e Scutellospora heterogama

\begin{tabular}{|c|c|c|c|c|c|c|}
\hline \multirow{3}{*}{ Porta-enxerto } & \multicolumn{3}{|c|}{ Comprimento de raízes } & \multicolumn{3}{|c|}{ Comprimento da parte área } \\
\hline & Testemunha & $\begin{array}{c}\text { Glomus } \\
\text { etunicatum }\end{array}$ & $\begin{array}{l}\text { Scutellospora } \\
\text { heterogama }\end{array}$ & Testemunha & $\begin{array}{c}\text { Glomus } \\
\text { etunicatum }\end{array}$ & $\begin{array}{c}\text { Scutellospora } \\
\text { heterogama }\end{array}$ \\
\hline & \multicolumn{3}{|c|}{$\mathrm{cm} \mathrm{pl}^{-1}$} & \multicolumn{3}{|c|}{$\mathrm{cm} \mathrm{pl}^{-1}$} \\
\hline SO4 & $44,42 \mathrm{aB}$ & $50,33 \mathrm{bA}$ & $52,83 \mathrm{aA}$ & $116,92 \mathrm{Ab}$ & 143,58 bA & $157,58 \mathrm{aA}$ \\
\hline Paulsen 1103 & $39,25 \mathrm{bB}$ & $43,75 \mathrm{cA}$ & $43,75 \mathrm{bA}$ & $103,67 \mathrm{aB}$ & $121,25 \mathrm{cA}$ & $131,33 \mathrm{cA}$ \\
\hline $043-43$ & $44,50 \mathrm{aC}$ & $59,00 \mathrm{aA}$ & $53,00 \mathrm{aB}$ & $115,25 \mathrm{aC}$ & $200,25 a A$ & 143,25 abB \\
\hline C.V. (\%) & \multicolumn{3}{|c|}{19,54} & \multicolumn{3}{|c|}{22,41} \\
\hline
\end{tabular}

Médias seguidas por letra maiúscula distinta na linha e minúscula na coluna, dentro da variável comprimento de raízes, diferem significativamente pelo teste de Duncan, p 0,05 .

Médias seguidas por letra maiúscula distinta na linha e minúscula na coluna, dentro da variável comprimento da parte aérea, diferem significativamente pelo teste de Duncan, p $\leq, 05$.

Tabela 4. Diâmetro de colo de porta-enxertos de videira Vitis sp. não submetidos à inoculação (Testemunha) e com inoculação de fungos micorrízicos arbusculares Glomus etunicatum e Scutellospora heterogama

\begin{tabular}{|lccc|}
\hline & \multicolumn{3}{c}{ Diâmetro do Colo } \\
\cline { 2 - 4 } $\begin{array}{l}\text { Porta- } \\
\text { enxerto }\end{array}$ & Testemunha & $\begin{array}{c}\text { Glomus } \\
\text { etunicatum } \\
\text { mm }\end{array}$ & $\begin{array}{c}\text { Scutellospora } \\
\text { heterogama }\end{array}$ \\
\hline S04 & $2,10 \mathrm{bB}$ & $3,69 \mathrm{bA}$ & $3,74 \mathrm{bA}$ \\
\hline Paulsen 1103 & $2,60 \mathrm{bB}$ & $3,72 \mathrm{bA}$ & $3,69 \mathrm{bA}$ \\
\hline $043-43$ & $3,68 \mathrm{aC}$ & $5,74 \mathrm{aA}$ & $4,60 \mathrm{aB}$ \\
\hline C.V. (\%) & & 13,66 & \\
\hline
\end{tabular}

Médias seguidas por letra maiúscula distinta na linha e minúscula na coluna diferem significativamente pelo teste de Duncan, $\mathrm{p} \leq 0,05$

Para a matéria fresca da parte aérea, as plantas Paulsen 1103 e SO4 proporcionaram maior massa quando inoculadas com G. etunicatum e $S$. heterogama, comparativamente àquelas não inoculadas. O PE $043-43$ proporcionou maior matéria fresca quando submetido à inoculação com o FMA G. etunicatum (Tabela 1). Agostini (2002), trabalhando com as cultivares 101-14 e Paulsen 1103 também observou eficiência significativa dos FMA sobre a matéria fresca aérea dos PE. Têm sido relatadas diferenças significativas entre as espécies de FMA na promoção do crescimento e do desenvolvimento de uma mesma espécie vegetal, sendo interpretadas como especificidade funcional (Lindermann e Davis, 2001, Locatelli e Lovato, 2002; Silveira et al., 2002). Nas condiçôes deste estudo, as respostas diferenciadas observadas da cultivar $\mathrm{PE}$, segundo a espécie de FMA inoculada, são devidas à compatibilidade funcional entre os simbiontes.

Para a matéria seca da parte aérea, os fungos G. etunicatum e $S$. heterogama promoveram aumento da massa dos PE SO4 e 043-43, mas não houve diferenças significativas sobre o crescimento do Paulsen 1103, quando comparadas às plantas testemunhas. $\mathrm{O}$ comportamento distinto da cultivar PE Paulsen 1103 para a matéria seca das raízes em relaçáo à sua matéria fresca (Tabela 2) deveu-se provavelmente ao fato dos fungos promoverem e auxiliarem na absorção de água pelas plantas micorrizadas, sendo a característica expressa na matéria fresca da planta (Augé, 2001; Silveira et al., 2002).

Alguns autores (SMith e Read, 1997; Silveira et al., 2002) relataram o potencial dos FMA em promover maior absorção e conteúdo de água sobre a biomassa fresca da planta. Augé (2001) observou que a simbiose micorrízica proporcionou alteraçóes nas taxas de absorção de água em plantas hospedeiras, com consequentes efeitos na hidratação dos tecidos, na biomassa fresca e na fisiologia das folhas. Tais relatos corroboram os resultados deste trabalho.

Em videiras, Agostini (2002) e Zemkle et al. (2003) afirmam que os FMA podem causar aumento de crescimento na produçâo de matéria seca da parte aérea da planta. Em plantas cítricas, Souza et al. (2005) declaram a possibilidade de incremento da matéria seca aérea com o emprego de FMA sobre o porta-enxerto Flying Dragon. SiLva et al. (2004), trabalhando com maracujazeiro-doce, observaram que os FMA têm capacidade aumentar a taxa fotossintética da planta, incrementando a matéria seca da parte área.

Plantas submetidas à inoculação com $G$. etunicatum e S. heterogama proporcionaram matéria fresca e seca das raízes semelhante entre si e significativamente superior à testemunha para os PE SO4 e 043-43, enquanto para o PE Paulsen 1103 não foram observadas diferenças significativas entre plantas inoculadas e não inoculadas (Tabela 2). Estes resultados comprovam que os benefícios oriundos da simbiose dependem da combinação específica entre espécie de FMA e a variedade PE utilizada.

Siqueira et al. (1998) afirmam que a inoculação das plantas pode promover aumentos da biomassa seca, que podem variar de $10 \%$ a $800 \%$, e as maiores e mais consistentes respostas foram observadas em plantas jovens, na fase de viveiro. Tais relatos corroboram os resultados neste trabalho, uma vez que as plantas PE S04 e 043-43 submetidas à inoculação com os FMA proporcionaram maior matéria seca, atribuída provavelmente à maior área foliar das plantas inoculadas que, juntamente com o aumento da altura, conferiram alto acúmulo de biomassa seca, em resposta à maior produçáo de fotoassimilados (Minhone e Auler, 2003). 
Os FMA testados aumentaram o comprimento do sistema radicular e da parte área das plantas, não diferindo entre si G. etunicatum e S. heterogama para os PE Paulsen 1103 e S04. No 043-43 verificou-se maior eficiência do FMA G. etucicatum em promover o crescimento do PE, comparativamente às plantas inoculadas com $S$. heterogama e as plantas testemunhas (Tabela 3). Segundo SouzA (2000), os FMA podem estar envolvidos nos processos hormonais das plantas, interferindo na síntese e translocação de fitormônios e, com isto, aumentando em quantidade a emissão de raízes. Esta afirmaçáo confirmou-se nesse experimento, onde os PE com FMA tiveram maior estímulo à formação de raízes em relação aos PE sem FMA. GeNdiah (1991) também verificou que mudas de videira ao serem inoculadas com FMA tendem a ter maior comprimento radicular e crescimento da parte aérea que as não submetidas à inoculação.

Em relação ao diâmetro de colo, verifica-se na tabela 4 que os FMA S. heterogama e Glomus etucicatum proporcionaram maior diâmetro de colo para todos os $\mathrm{PE}$, quando comparada às plantas não colonizadas. Na média geral, o PE 043-43, independentemente do tratamento, conferiu maior vigor, permitindo a possibilidade de redução do período para a enxertia das mudas. SiLVEIra et al. (2002), trabalhando com PE de abacateiro verificaram que a inoculação de Scutellospora heterogama também aumentou o diâmetro do colo das plantas, se comparado às testemunhas.

A propensão para valores superiores do PE 043-43 comparado às demais cultivares, para todas as variáveis analisadas no trabalho (Tabelas 1, 2, 3 e 4) deve-se, provavelmente, ao diferente mecanismo genético que as cultivares porta-enxerto manifestam (GiovaninNI, 2008), independente da interação com FMA.

As plantas colonizadas por FMA tiveram melhor absorção de nutrientes, principalmente N, P e K comparada às não-colonizadas (Tabela 5), o que justifica o aumento crescimento inicial dos PE micorrizados, conforme descrito por Ozdemir et al. (2010). Essa diferença de crescimento pode ser atribuída ao efeito das hifas externas dos FMA possibilitarem ao sistema radicular das plantas hospedeiras uma absorção de nutrientes além da zona de seus pelos radiculares (Siqueira et al., 2002). Schubert et al. (1990) e
KARAGIANNIDIs et al. (1995) também constataram resposta positiva à absorção de $\mathrm{P}$ quando da inoculação de FMA em PE de videira e Petgen et al. (1998) obtiveram incremento nos níveis foliares de $\mathrm{P}, \mathrm{Zn}$ e $\mathrm{Cu}$ no porta-enxerto $\mathrm{SO} 4$ submetidas à inoculação com Glomus mosseae.

A concentração dos nutrientes nos tecidos vegetais, em todos os PE, ficou acima e na faixa normal, exceto para o $\mathrm{Ca}^{2+}$ cuja concentraçấo ficou abaixo para a cultura da videira (Tedesco et al., 2004). O PE 043-43 propiciou valores sensivelmente menores para todos os nutrientes, possivelmente em função do efeito diluiçáo decorrente do seu maior vigor. Para NunEs et al. (2008b), o maior crescimento das plantas pode acarretar efeito diluição dos nutrientes nos tecidos vegetais.

A maior absorção de nitrogênio pelas plantas inoculadas com as espécies de FMA (Tabela 5) contribuiu para que esses tratamentos proporcionassem maior altura, diâmetro e biomassa fresca e seca da parte aérea e raízes, quando comparados à testemunha. Minhoni e Auler (2003) destacaram que os FMA são vitais para as plantas, pois podem proporcionar aumentos de até $25 \%$ na absorção de N (Siqueira et al., 2002), 80\% na absorção de fósforo (Marschner e Dell, 1994) e de 60\% para o potássio (SIQUEIRA et al., 2002). Embora nos tratamentos com FMA tenham ocorrido maiores percentuais de macronutrientes nos tecidos vegetais, em relação à testemunha, seus índices não alcançaram os percentuais ótimos mostrados por Marschner e Dell (1994) e Siqueira et al. (2002), devido possivelmente ao período curto do experimento e/ou a limitação de exploração das micorrizas ao solo em função das plantas estarem contidas em sacos plásticos.

De acordo com Tedesco et al. (2004), o fósforo e o potássio são elementos com grande mobilidade no tecido vegetal, porém são pouco móveis no solo, além de terem baixa solubilidade. Dessa forma, ao propiciarem maior absorção desses elementos, os FMA assumem papel fundamental para os vegetais (Minhoni e Auler, 2003).

Segundo Souza et al. (2005), a concentração dos elementos $\mathrm{Ca}^{2+} \mathrm{e} \mathrm{Mg}^{2+}$ em plantas de Citrus submetidas à inoculação com FMA é semelhante à concentração presente em plantas não colonizadas, devido à inibição da absorção desses elementos em vista de um efeito-tampão

Tabela 5. Teores nutricionais da parte aérea de porta-enxertos de videira (Vitis sp.) SO4, Paulsen 1103 e 043-43 não submetidos à inoculação (T) e com inoculação de fungos micorrízicos arbusculares: Ge: Glomus etunicatum e Sh: Scutellospora heterogama

\begin{tabular}{|c|c|c|c|c|c|c|c|c|c|}
\hline \multirow{3}{*}{$\begin{array}{l}\text { Elemento } \\
\text { químico }\end{array}$} & \multicolumn{9}{|c|}{ Teores Nutricionais } \\
\hline & S04 - T & P1103 - T & 043-43-T & SO4-Ge & P1103 - Ge & $043-43-\mathrm{Ge}$ & SO4 - Sh & P1103 - Sh & 043-43 - Sh \\
\hline & \multicolumn{9}{|c|}{$\%$} \\
\hline$N$ & $1,7 \mathrm{bc}(1)$ & $1,9 \mathrm{~b}$ & $1,4 \mathrm{c}$ & $2,4 \mathrm{a}$ & $2,1 \mathrm{ab}$ & $1,5 \mathrm{c}$ & $2,0 a b$ & $2,2 \mathrm{a}$ & $1,6 \mathrm{c}$ \\
\hline$P$ & $0,52 b$ & $0,57 \mathrm{~b}$ & $0,30 \mathrm{c}$ & $0,72 \mathrm{a}$ & $0,60 \mathrm{~b}$ & $0,35 c$ & $0,67 \mathrm{a}$ & $0,63 a b$ & $0,38 \mathrm{c}$ \\
\hline K & $1,6 \mathrm{~b}$ & $1,5 b$ & $1,1 \mathrm{c}$ & $2,0 \mathrm{a}$ & $1,9 \mathrm{a}$ & $1,3 c$ & $1,5 \mathrm{~b}$ & $1,7 \mathrm{ab}$ & $1,2 \mathrm{c}$ \\
\hline $\mathrm{Ca}$ & $1,2 \mathrm{a}$ & $1,2 \mathrm{a}$ & $1,3 \mathrm{a}$ & $1,2 \mathrm{a}$ & $1,3 \mathrm{a}$ & $1,2 \mathrm{a}$ & $1,4 \mathrm{a}$ & $1,2 \mathrm{a}$ & $1,2 \mathrm{a}$ \\
\hline $\mathrm{Mg}$ & $0,40 \mathrm{~b}$ & $0,40 \mathrm{~b}$ & $0,33 c$ & $0,39 \mathrm{~b}$ & $0,46 a$ & $0,35 c$ & $0,38 \mathrm{~b}$ & $0,47 a$ & $0,34 \mathrm{c}$ \\
\hline
\end{tabular}

(') Médias seguidas por letra minúscula distinta na linha diferem significativamente pelo teste de Duncan, $p \leq 0,05$. 
proporcionado pelos fungos. Tais relatos estáo em concordância com os resultados deste trabalho, exceto para o PE Paulsen 1103 submetidos à inoculação com Scutellospora heterogama, onde foi verificada maior concentração de $\mathrm{Mg}^{2+}$ nos tecidos vegetais. NunEs et al. (2008a) relatam que plantas de PE de pessegueiro, inoculadas com FMA tiveram níveis baixos de cálcio e magnésio nos tecidos das plantas, corroborando com a informação que os FMA não aumentam ou intensificam a absorção desses elementos.

Ao utilizar-se FMA na inoculação de PE de videira é de fundamental importância a escolha da espécie de fungo, pois há variação na eficiência da simbiose em função dela (Agostini, 2002). Na micropropagação comercial de frutíferas utilizam-se, normalmente, substratos ricos em matéria orgânica, os quais possuem alta concentração de nutrientes, com vistas a promover crescimento rápido e alta taxa de sobrevivência das plantas. Entretanto, esses substratos têm efeito negativo no estabelecimento das micorrizas, causando baixos índices de colonizaçáo radicular (SMITH e READ, 1997). No presente estudo, as duas espécies de FMA foram eficientes em promover o crescimento vegetativo dos $\mathrm{PE}$, indicando serem interessantes para utilização em um sistema de produçáo de mudas micropropagadas, quando inoculadas na fase de aclimatização das plantas.

\section{CONCLUSÃO}

Os FMA Glomus etunicatum e Scutellospora heterogama proporcionam melhor nutrição e maior crescimento vegetativo dos PE de videira. Os benefícios oriundos da simbiose dependem da combinação específica entre o isolado fúngico e a variedade PE utilizada, sendo o 043-43 beneficiado preponderantemente pelo FMA Glomus etunicatun e o SO4 e Paulsen 1103 por Glomus etunicatum e Scutellospora heterogama.

\section{AGRADECIMENTOS}

Ao Conselho Nacional de Desenvolvimento Científico e Tecnológico - CNPq, pela concessão de auxílio financeiro ao desenvolvimento do projeto.

\section{REFERÊNCIAS}

AGOSTINI, S. Fungos micorrízicos arbusculares e o desenvolvimento vegetativo de porta-enxertos de videira. 2002. 57f. Dissertação (Mestrado em Fitotecnia), Faculdade de Agronomia, Universidade Federal do Rio Grande do Sul, Porto Alegre.

BOTELHO, R.V.; MAIA, A.J.; PIRES. E.J.P.; TERRA, M.M.; SCHUCK, E. Estaquia do porta-enxerto de videira '43-43' ( $V$. vinifera $\mathrm{x} V$. rotundifolia) resistente à Eurhizococchus brasiliensis. Revista Brasileira de Fruticultura, v.27, p.480-483, 2005.
AUGÉ, R.M. Water relations, drought and vesicular-arbuscular mycorrhizal symbiosis. Mycorrhiza, v.11, p.3-42, 2001.

GENDIAH, H.M. Stimulating root growth of grape hardwood cutting by using endomycorrhizal fungi. Annals of Agricultural Science, v.29, p.1713-1723, 1991.

GIOVANINNI, E. Produção de uvas para vinhos, suco e mesa. 3.ed. Porto Alegre: Renascença, 2008. 364p.

KARAGIANNIDIS, N.; NIKOLAOU, N.; MATTHEOU, A. Influence of three VA-mycorrhiza species on the growth and nutrient uptake of three grapevine rootstocks and one table grape cultivar. Vitis, v.39, p. 85-89, 1995.

LINDERMANN, R.G.; DAVIS, A. Comparative response of selected grapevine rootstocks and cultivars to inoculation with different mycorrhizal fungi. American Journal of Enology and Viticulture, v.52, p.8-11, 2001.

LOCATELLI, L.M.; LOVATO, P.M. Inoculação micorrízica e aclimatização de dois porta-enxertos de macieira micropropagados. Pesquisa Agropecuária Brasileira, v.37, p.177-184, 2002.

MARSCHNER, H.; DELL, B. Nutrient uptake in mycorrhizal symbiosis. In: ROBSON, A.D.; ABBOT, L.K.; MALAJCZUK, N. (Ed.). Management of mycorrhizas in agriculture, horticulture and forestry. 2.ed. Dordrecht: Kluwer Academic Publishers, 1994. p. $89-102$.

MENGE, J.A. Inoculum production. In: POWEL, C.L.; BAGYARAJ, D.J. (Ed.). VA mycorrhiza. Boca Raton: CRC Press, 1984. p.187-203.

MINHONI, M.T.A.; AULER, P.A.M. Efeito do fósforo, fumigação do substrato e fungo micorrízico arbuscular sobre o crescimento de plantas de mamoeiro. Revista Brasileira de Ciência do Solo, v.27, p.841-847, 2003.

NOGALES, A.; AGUIRREOLEA, J.; MARIA, E.S.; CAMPRUBI, A.; CALVET, C. Response of mycorrhizal grapevine to Armillaria mellea inoculation: disease development and polyamines. Plant and Soil, v.317, p.177-187, 2009.

NUNES, J.L.S.; SOUZA, P.V.D.; MARODIN, G.A.B.; FACHINELLO, J.C. Incremento no desenvolvimento do portaenxerto de pessegueiro "Aldrighi" por fungos micorrízicos arbusculares autóctones. Ciência e Agrotecnologia, v.32, p.1787-1793, 2008a.

NUNES, J.L.S.; SOUZA, P.V.D.; MARODIN, G.A.B.; FACHINELLO, J.C. Inoculação de fungos micorrízicos arbusculares em porta-enxerto de pessegueiro cv Okinawa. Revista Brasileira de Fruticultura, v.30, p.1100-1106, 2008b.

OZDEMIR, G.; AKPINAR, G.; SABIR, A. BILIR, H.; TANGOLAR, S.; ORTAS, I. Effect of inoculation with mycorrhizal fungi on growth and nutrient uptake of grapevine genotypes (Vitis spp.). European Journal of Horticultural Science, v.75, p.103-110, 2010.

PETGEN, M.; SCHOROPP, A.; GEORGE, E. Einfluss unterschiedlicher inokulationstiefen mit dem arbuskulären mykorrhizapilz Glomus mosseae auf die mukorrhizierung bei Reben (Vitis sp.) in Wurzelbeobachtungskästen. Vitis, v.37, p.99-105, 1998. 
SAGGIN JUNIOR, O.J.; LOVATO, P.E. Aplicação de micorrizas arbusculares na produção de mudas e plantas micropropagadas. In: SIQUEIRA, J.O.; MOREIRA, F.M. S.; LOPES, A.S.; GUILHERME, L.R.L.; FAQUIM, V. Inter-relação fertlidade, Biologia do Solo e Nutrição de Plantas, Viçosa: SBCS: UFLA. DCS, 1999. p.230-261.

SCHREINER, R.P. Effects of native and nonnative arbuscular mycorrhizal fungi on growth and nutrient uptake of 'Pinot noir' (Vitis vinifera L.) in two soils with contrasting levels of phosphorus. Applied Soil Ecology, v.36, p.205-215, 2007.

SCHUBERT, A.; MAZZITELI, M.; ARIUSSO, O.; EYNARD, I. Effects of vesicular arbuscular mycorrhizal fungi on micropropagated grapevine: influence of endophyte strain, $\mathrm{P}$ fertilization and growth medium. Vitis, v.29, p.5-13, 1990.

SILVA, A.L.; DOAZAN, J.P. Une méthode d'irradiation aux rayons gamma appliquée à des portegreffes de vigne in vitro. Journal International des Sciences de la Vigne et du Vin, v.29, p.1-9, 1995.

SILVA, M.A.; CAVALCANTE, U.M.T.; SILVA, F.S.B.; SOARES, S.A.G.; MAIA, L.C. Crescimento de mudas de maracujazeiro-doce (Passiflora alata Curtis) associadas a fungos micorrízicos arbusculares (Glomeromycota). Acta Botanica Brasilica, v.18, p.981-985, 2004.

SILVEIRA, S.V.; SOUZA, P.V.D.; KOLLER, O.C. Influência de fungos micorrízicos arbusculares sobre o desenvolvimento vegetativo de abacateiro. Pesquisa Agropecuária Brasileira, v.37, p.303-309, 2002.

SIQUEIRA, J.O.; SAGGIN-JÚNIOR, O.J.; FLORES-AYLAS, W.W.; GUIMARÁES, P.T.G. Arbuscular mycorrhizal inoculation and superphosphate application influence plant development and yield of cofee in Brazil. Mycorrhiza, v.7, p.293-300, 1998.
SIQUEIRA, J.O.; LAMBAIS, M.R.; STÜRMER, S.L. Fungos micorrízicos arbusculares: origem e características dos fungos Glomaleanos. Biotecnologia, Ciência e Desenvolvimento, v.25, p.12-21, 2002.

SMITH, S.E.; READ, D.J. Mycorrhizal symbiosis. 2.ed. San Diego: Academic, 1997. 605p.

SOUZA, P.V.D. Interação entre micorrizas arbusculares e ácido giberélico no desenvolvimento vegetativo de plantas de citrange carrizo. Ciência Rural, v.30, p.783-787, 2000.

SOUZA, P.V.D.; CARNIEL, E.; SCHMITZ, J.A.K.; SILVEIRA, S.V. Influência de substratos e fungos micorrízicos arbusculares no desenvolvimento do porta-enxerto Flying Dragon (Poncirus trifoliata, var. mosntruosa Swing). Revista Brasileira de Fruticultura, v.27, p.285-287, 2005.

TEDESCO, M.J.; GIANELLO, C.; ANGHINONI, I.; BISSANI, C.A.; CAMARGO, F.A.O, WIETHÖLTER, S. Manual de adubaçáo e calagem para os Estados do Rio Grande do Sul e de Santa Catarina. Porto Alegre: UFRGS, 2004. 400p.

THOMAS, P.; RAVINDRA, M.B. Effects of pruning or removal of in vitro formed roots on ex vitro regeneration and growth in micropropagated grapes. Plant Cell Tissue and Organ Culture, v.51, p.177-180, 1997.

ZEMKLE, J.M.; PEREIRA, F.; LOVATO, P.E.; SILVA, A.L. Avaliação de substratos para inoculação micorrízica e aclimatização de dois porta-enxertos de videira micropropagados. Pesquisa Agropecuária Brasileira, v.38, p.1309-1315, 2003. 